\title{
Impulsivity of Noise due to Single Lightweight Vehicles Transit on Transverse Rumble Strip
}

\author{
N. Darus ${ }^{1, *}, Z$. Haron ${ }^{1}, K$. Yahya $^{1}$, M.H. Abd Halil ${ }^{1}$, W.M.A. Norudin ${ }^{1}$, M.H. Othman ${ }^{2}$, \\ and M.A. Hezmi ${ }^{1}$ \\ ${ }^{1}$ Faculty of Civil Engineering, Universiti Teknologi Malaysia, 81310 Johor Bahru, Johor, Malaysia \\ ${ }^{2}$ Faculty of Civil and Environmental Engineering, Universiti Tun Hussein Onn Malaysia, 86400 Parit \\ Raja, Batu Pahat Johor, Malaysia
}

\begin{abstract}
Transverse Rumble Strips (TRS) acts as safety device that alert inattentive drivers from potential dangers. However, the noise produced due to TRS was reported as noise annoyance among the nearby residents lived adjacent to roadways. Thus, this paper investigates the impulsivity characteristic of noise due to single lightweight vehicles transit on TRS. The objectives of this study are to determine the increase of sound level and to evaluate the impulsivity of noise. Two TRS profiles namely middle overlapped (MO) and middle layer overlapped (MLO) were selected. Three types of single lightweight vehicles which include hatchback, sedan and multipurpose (MPV) were tested at speed of 30,50 and $70 \mathrm{~km} / \mathrm{h}$. The sound level was measured using sound level meter (SLM). Noise indices such as $\mathrm{L}_{\text {Aeq, }}$ LAIeqT, LAImax, LAFmax and LASmax were obtained from the measurement. This study considered the differences of $\mathrm{L}_{\mathrm{AImax}}-\mathrm{L}_{\mathrm{AFmax}}>$ $2 \mathrm{dBA}, \mathrm{L}_{\mathrm{AFmax}}-\mathrm{L}_{\text {Aeq }} \geq 10 \mathrm{dBA}, \mathrm{L}_{\text {AleqT }}-\mathrm{L}_{\text {Aeq }} \geq 2 \mathrm{dBA}$ and $\mathrm{L}_{\text {AImax }}-\mathrm{L}_{\mathrm{ASmax}}>$ $6 \mathrm{dBA}$ to evaluate the impulsivity of noise. It was found that TRS increased the sound level by at most of 6dBA. Furthermore, all single lightweight vehicles transit on TRS show significant impulsive characteristic. These results proved that TRS produce significant impact to the nearby residents.
\end{abstract}

\section{Introduction}

Transverse rumble strip (TRS) is one of the configurations of rumble strip installed on roadways apart from centreline rumble strip (CRS) and shoulder rumble strip (SRS). In Malaysia, TRS is commonly installed with various types of profiles such as middle overlapped, middle layer overlapped and raised rumble strip. It is usually installed at residential or urban area, which acts as one of the countermeasures in reducing traffic accident [1]. It alerts the inattentive and distracted drivers from potential dangers by transmitting sound and vibration through a vehicle. The sound and vibration will produce once the vehicle's tire interacts with the TRS surface. Installation of TRS helps to reduce accidents at pedestrian crosswalks, head-on collision, run off road crashes, fatal crashes and other potential accidents [2-6].

\footnotetext{
* Corresponding author: nddarus@yahoo.com
} 
Several complaints were made by the nearby residents who lived adjacent to the roadways regarding the rumble strips noise annoyance. Thus, attempts had been made to find the extent of increase sound level, $\mathrm{L}_{\text {Aeq }}$ toward the noise annoyance incur by the rumble strip installations. In the case of CRS, a study reported that noise produced is a trade-off from the safety as it was $60 \mathrm{dBA}$ at distance of $60 \mathrm{~m}$ away from roadway [7]. Furthermore, it was also found that noise produced is enough to be noticed by a normal human at a distance up to $45 \mathrm{~m}$ away from the CRS [8]. On the other hand, TRS has increased noise level by $7 \mathrm{dBA}$ at a distance of $15 \mathrm{~m}$ [9]. Besides that, installation of TRS at residential areas may generate noticeable noise that can be detected by the nearby residents as much as $4.5 \mathrm{dBA}$ at $70 \mathrm{~km} / \mathrm{h} \mathrm{[10].}$

Beside the increase in sound level, most guidelines suggest the extent of impulsive characteristic of sound in order to examine the extent of noise annoyance. In Malaysia, Department of Environment (DOE) provides a penalty of 5dBA to the measured equivalent continuous A-weighted sound pressure level, $\mathrm{L}_{\text {Aeq }}$ for estimating annoyance [11]. However, impulsive characteristic of noise produced by the TRS application is very limited. Impulsive characteristic of noise annoys the nearby residents more than the normal continuous noise. It is also must be included in the guidelines by the local authority. Therefore, this study was conducted to investigate the impulsivity characteristic of noise due to single lightweight vehicles transit on TRS by determining the increase of sound level and evaluating the impulsivity of noise.

\section{Methodology}

\subsection{Sound level due to single lightweight vehicles}

In this study, middle overlapped (MO) and middle layer overlapped (MLO) were selected. The details of both TRS types were shown in Table 1. The TRS and road surfaces at the selected sites were in good and dry conditions. Both roadways at two sites are straight as required by the ISO 13325 [12]. Meanwhile, Table 2 shows the three types of selected test vehicle such as hatchback (Axia), sedan (Saga) and multipurpose (Alza). These vehicles were selected because they are typical cars used on the roadways in Malaysia. The same test vehicles were used throughout the measurement for both TRS types in order to avoid the effect of vehicle type and road condition [13]. All single vehicles were drove over both TRS types at running speeds of 30,50 and $70 \mathrm{~km} / \mathrm{h}$. These running speeds were tested as required by the PWD guideline [14].

A Type 1 Pulsar Model 33 sound level meter (SLM) was used to measure the sound level due these single lightweight vehicles transit on the TRS. The SLM was calibrated prior and after measurement using Model 105 acoustic calibrator in order to avoid reading error. It was set up at $1.5 \mathrm{~m}$ above the ground level and $7.5 \mathrm{~m}$ away from the middle of nearest travel lane as shown in Fig. 1. Each site has two measurement points where the distance between Point 1 and Point 2 is $300 \mathrm{~m}$ which is sufficient for noise dissipation [15]. The measurement was repeated three times for each running speed in order to obtain the average value. The single vehicle test was conducted using controlled pass-by, a method derived from coast-by method [12]. This method can directly measure the tire-pavement noise due to single vehicle in free flowing and at constant vehicle speed. 
Table 1. TRS profile types.

\begin{tabular}{|c|c|c|}
\hline $\begin{array}{c}\text { Types of } \\
\text { TRS } \\
\text { profiles }\end{array}$ & 3 & 3 \\
\hline Thickness, mm & 600 & 2400 \\
\hline Width, mm & 2350 & 2800 \\
\hline Spacing, mm & 3350 & 30 \\
\hline Length, mm & 33 & $200 \mathrm{~mm}$ \\
\hline Number of strip & & \\
\hline
\end{tabular}

Table 2. Details of test vehicle.

\begin{tabular}{|c|c|c|c|}
\hline $\begin{array}{c}\text { Types of } \\
\text { test } \\
\text { vehicle }\end{array}$ & Perodua Axia & Proton Saga & Perodua Alza \\
\hline Model & 2016 & 2013 & 2007 \\
\hline Year & 840 & 1017 & 1145 \\
\hline Weight, kg & 1.0 & 1.3 & 1.5 \\
\hline Displacement, cc & $175 / 50 \mathrm{R} 14$ & $195 / 55 \mathrm{R} 15$ & $185 / 55 \mathrm{R} 15$ \\
\hline Tire Size &
\end{tabular}

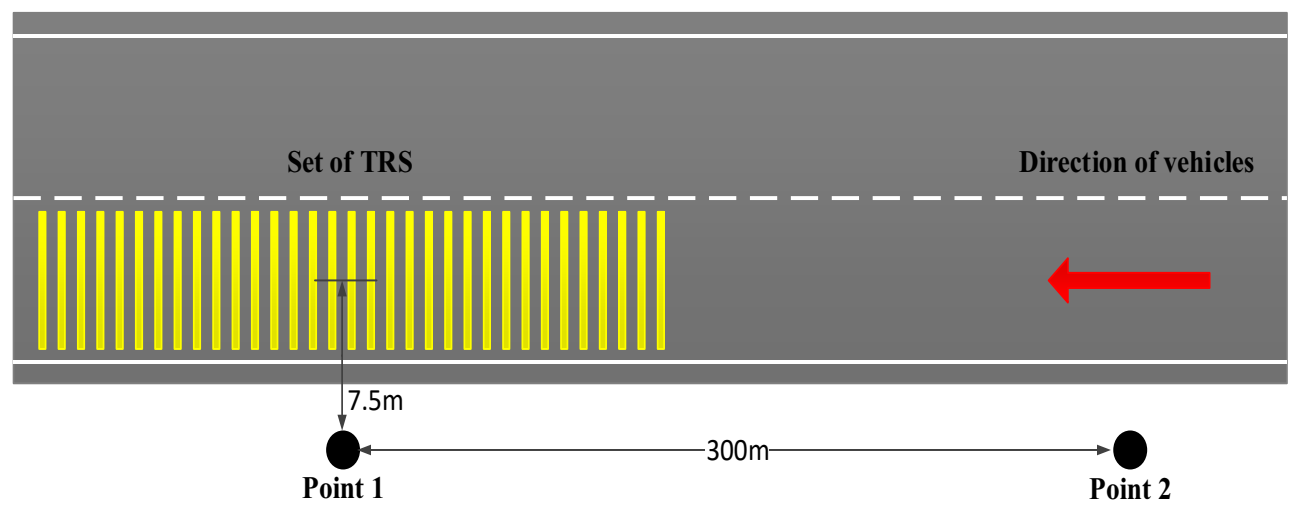

Fig. 1. Measurement layout. 


\subsection{Impulsivity due to single lightweight vehicles}

The impulsive characteristic of noise was detected objectively using the following methods. The first one is by comparing the A-weighted maximum noise level between fast response $\left(\mathrm{L}_{\mathrm{AFmax}}\right)$ with the equivalent $\mathrm{A}$-weighted sound pressure level $\left(\mathrm{L}_{\mathrm{Aeq}}\right)$, difference value of $\geq 10 \mathrm{~dB}$ [16]. Besides that, the difference between A-weighted impulse sound pressure level, determined with time-weighting characteristic I $\left(\mathrm{L}_{\mathrm{AIeqT}}\right)$, averaged over the same time interval and $\mathrm{L}_{\mathrm{Aeq}}$ also can detect the impulsivity. A difference value of $\geq 2 \mathrm{~dB}$ would indicate an impulsive characteristic [17]. Meanwhile, the third method is by comparing $\mathrm{L}_{\mathrm{AFmax}}$ and A-weighted maximum impulse response $\left(\mathrm{L}_{\mathrm{AImax}}\right)$ with $>2 \mathrm{~dB}$ difference value [18]. The last method is by comparing A-weighted, slow, maximum sound level ( $\mathrm{L}_{\mathrm{ASmax}}$ ) with $\mathrm{L}_{\mathrm{AImax}}$. If the difference is $\geq 6 \mathrm{~dB}$, impulsive characteristic occurs [19].

\section{Results and discussions}

\subsection{Sound level due to single lightweight vehicles}

In this study, sound levels due to all types of single lightweight vehicles driven through both types of TRS were recorded by the SLM at Point 1. Fig. 2 to Fig. 7 shows the sound level $\left(\mathrm{L}_{\text {Aeq }}\right)$ versus time history of hatchback, sedan and MPV driven through MO and MLO and its differences with baseline (roadside sound level without TRS). The peak noise levels were shown at $6^{\text {th }}$ second when the vehicle was directly in front of SLM at Point 1. The $\mathrm{L}_{\text {Aeq }}$ values produced due to single vehicles driven through roadways with and without TRS were presented using solid and dotted lines respectively. It can be observed that MO has significant lower sound level increment with peak level of 2.4dBA (hatchback) as compared to MLO with peak level of 6.6dBA (MPV). Besides that, hatchback and sedan which has lower engine power recorded lower sound level increment as compared to MPV.

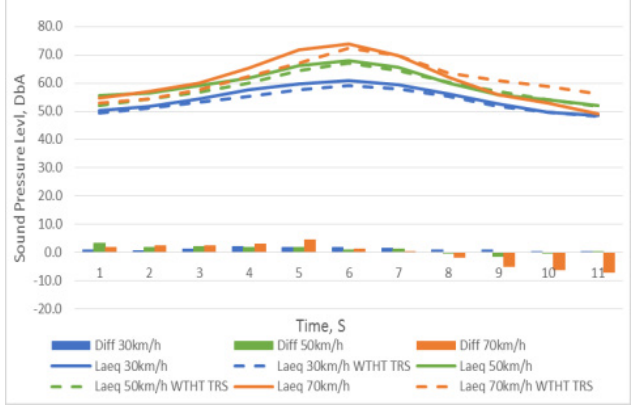

Fig. 2. $\mathrm{L}_{\mathrm{Aeq}}$ vs. time using hatchback at MO.

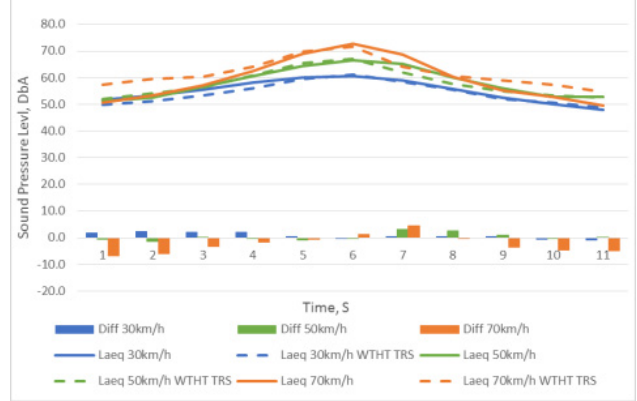

Fig. 4. LAeq vs. time using sedan at MO.

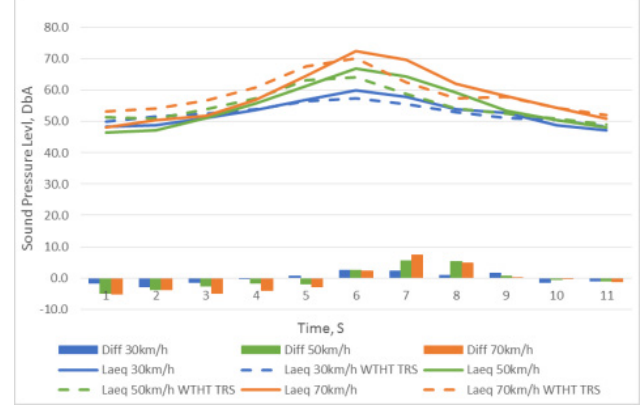

Fig. 3. $\mathrm{L}_{\mathrm{Aeq}}$ vs. time using hatchback at MLO.

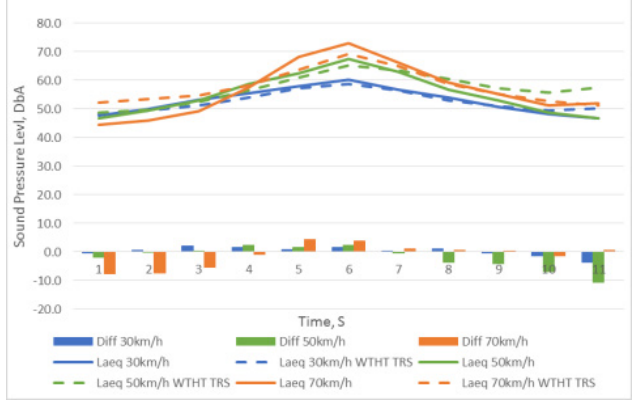

Fig. 5. LAeq vs. time using sedan at MLO. 


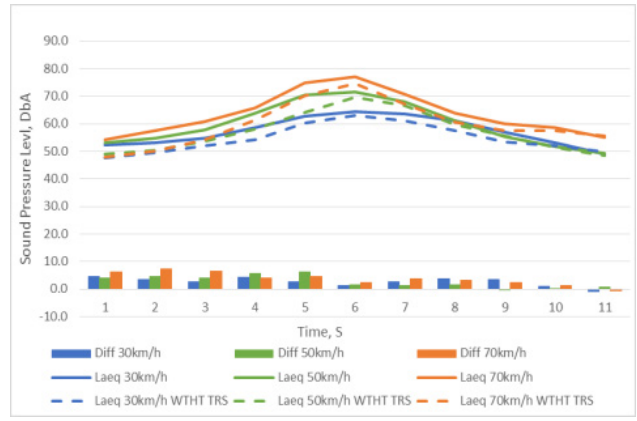

Fig. 6. LAeq vs. time using MPV at MO.

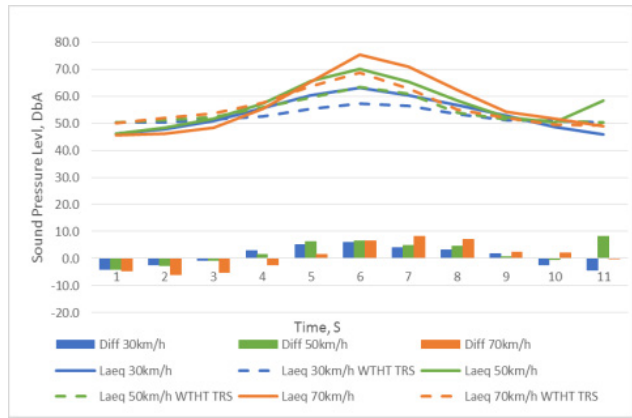

Fig. 7. LAeq vs. time using MPV at MLO.

Fig. 8 shows the relationship of average increment of $\mathrm{L}_{\text {Aeq }}$ and vehicle speeds for all vehicle types driven through MO and MLO. It is noted that the average increment of $\mathrm{L}_{\text {Aeq }}$ values for vehicles driven through MLO are higher than MO. It can be seen that only hatchback driven through both TRS types not recorded any increment for all vehicle speeds. At speeds of 30 and $50 \mathrm{~km} / \mathrm{h}$, the increments are very low or the same where the values are below $3 \mathrm{dBA}$. However, sedan at speed of $70 \mathrm{~km} / \mathrm{h}$ and MPV at all three speeds driven through both TRS types recorded increment over 6dBA. There are no significant increments for low power engine vehicles such as hatchback and sedan which can be annoyance to the nearby residents. It shows that the overall average increment of $\mathrm{L}_{\text {Aeq }}$ values do not give significant impact when measured with $\mathrm{L}_{\text {Aeq }}$ only.

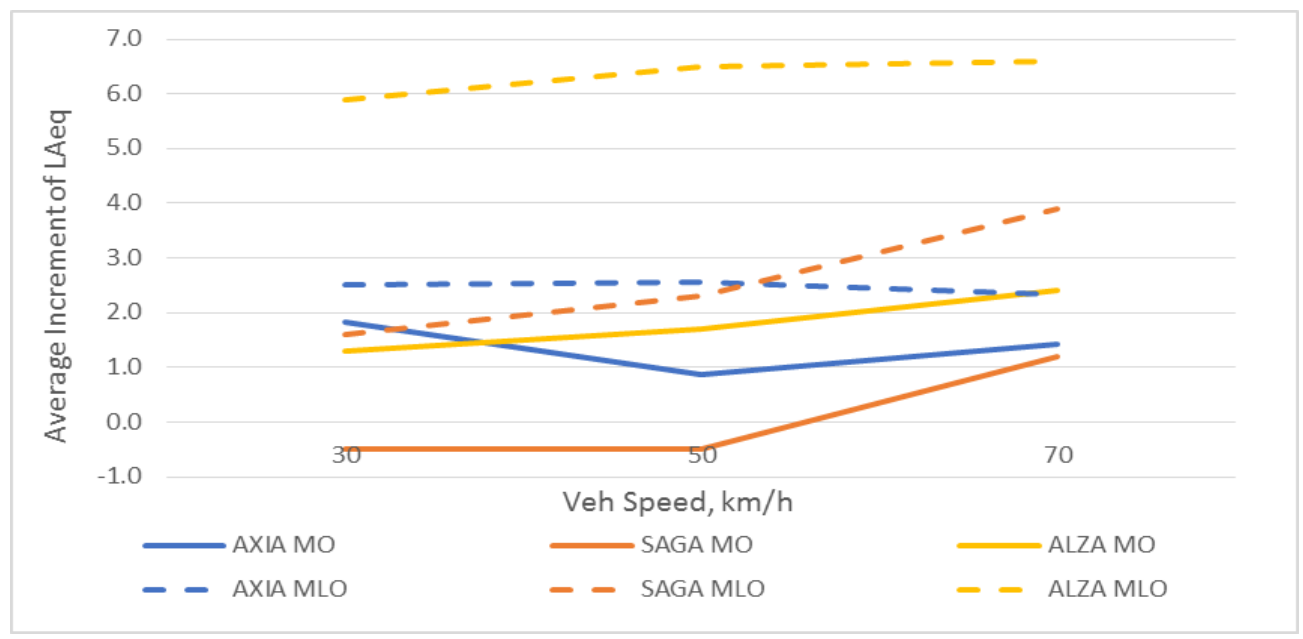

Fig. 8. Average increment of LAeq values versus vehicle speeds.

Other noise indices related to peak $\mathrm{L}_{\text {Aeq }}$ such as $\mathrm{L}_{\mathrm{AFmax}}, \mathrm{L}_{\mathrm{AImax}}, \mathrm{L}_{\mathrm{AIeqT}}$ and $\mathrm{L}_{\mathrm{ASmax}}$ were also evaluated. The values were compared with baseline of normal road ( $\mathrm{L}_{\mathrm{AFmaxw}}, \mathrm{L}_{\mathrm{AImaxw}}$, $\mathrm{L}_{\mathrm{AIeqTw}}$ and $\mathrm{LA}_{\text {Smaxw }}$ ) as in Table 3. Some of the values are characterized by an increment for all vehicle speeds. However, most of the values shows the increment at speed of 30 to $50 \mathrm{~km} / \mathrm{h}$ whereas decrement at speed of 50 to $70 \mathrm{~km} / \mathrm{h}$. This may be due to the values at higher speed were influenced by the sound produced by the power engine of the testing vehicles. Other than that, the values for all noise indices show decrement as compared to baseline at speed of $30 \mathrm{~km} / \mathrm{h}$. There are also values decrement for hatchback and sedan at noise indices of $\mathrm{L}_{\mathrm{AFmax}}, \mathrm{L}_{\mathrm{AImax}}$ and $\mathrm{L}_{\mathrm{ASmax}}$ as compared to MPV. This can be assumed that the TRS act as a sound damper when vehicles are moving at low speed and power engines. 
Table 3. Noise indices.

\begin{tabular}{|c|c|c|c|c|c|c|c|c|c|c|c|c|}
\hline $\begin{array}{l}\stackrel{0}{0} \\
\stackrel{0}{0} \\
\frac{0}{0}\end{array}$ & $\sum_{\infty}^{0}$ & 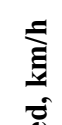 & 䒿 & 奠 & 尊 & 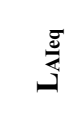 & 总 & 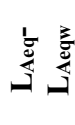 & 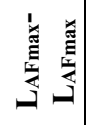 & 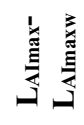 & 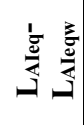 & 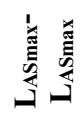 \\
\hline$>$ & & $\bar{n}$ & \multicolumn{10}{|c|}{ dBA } \\
\hline \multirow{6}{*}{ 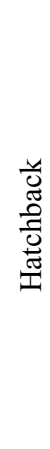 } & MO & \multirow{2}{*}{30} & 59.9 & 81.8 & 84.2 & 61.4 & 74.6 & 2.5 & -2.9 & -1.0 & 3.2 & -7.8 \\
\hline & MLO & & 61.0 & 73.6 & 77.4 & 61.8 & 68.7 & 1.8 & -3.7 & -3.5 & 1.9 & -6.1 \\
\hline & MO & \multirow{2}{*}{50} & 66.7 & 83.5 & 85.2 & 68.6 & 79.4 & 2.5 & 0.9 & 2.0 & 3.2 & 1.3 \\
\hline & MLO & & 68.1 & 86.0 & 87.3 & 69.1 & 83.9 & 0.9 & 7.3 & 6.4 & 1.2 & 9.6 \\
\hline & MO & \multirow{2}{*}{70} & 72.3 & 80.2 & 81.8 & 74.2 & 75.1 & 2.3 & 4.9 & 5.3 & 3.1 & 2.8 \\
\hline & MLO & & 73.9 & 75.3 & 77.5 & 75.6 & 73.1 & 1.5 & -9.3 & -9.4 & 2.6 & -5.1 \\
\hline \multirow{6}{*}{ 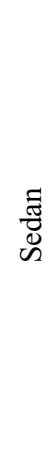 } & MO & \multirow{2}{*}{30} & 60.3 & 81.8 & 84.2 & 61.1 & 74.6 & 1.6 & -3.8 & -2.5 & 1.9 & -7.8 \\
\hline & MLO & & 60.6 & 74.7 & 78.6 & 61.4 & 69.0 & -0.5 & $\begin{array}{c}- \\
11.6\end{array}$ & -9.0 & -0.7 & $\overline{14.3}$ \\
\hline & MO & \multirow{2}{*}{50} & 67.6 & 83.6 & 85.2 & 69.3 & 80.6 & 2.3 & 1.0 & 2.0 & 3.5 & 2.5 \\
\hline & MLO & & 66.6 & 86.0 & 87.3 & 67.5 & 83.9 & -0.5 & 7.3 & 6.4 & -1.1 & 9.6 \\
\hline & MO & \multirow{2}{*}{70} & 73.1 & 82.3 & 85.5 & 75.6 & 75.3 & 3.9 & 4.3 & 6.2 & 5.9 & 0.7 \\
\hline & MLO & & 72.7 & 75.4 & 77.5 & 73.8 & 73.3 & 1.2 & -9.2 & -9.4 & -0.3 & -4.9 \\
\hline \multirow{6}{*}{$\stackrel{2}{\Sigma}$} & MO & \multirow{2}{*}{30} & 63.1 & 77.1 & 79.7 & 64.3 & 71.8 & 5.9 & -2.8 & -0.9 & 6.6 & -5.4 \\
\hline & MLO & & 64.5 & 83.6 & 84.4 & 65.3 & 81.4 & 1.3 & 14.3 & 13.5 & 1.5 & 14.4 \\
\hline & MO & \multirow{2}{*}{50} & 70.0 & 77.7 & 81.3 & 71.5 & 69.7 & 6.5 & 1.1 & 3.1 & 7.5 & -2.2 \\
\hline & MLO & & 71.5 & 78.6 & 80.3 & 72.6 & 76.3 & 1.7 & 5.1 & 6.2 & 2.1 & 4.5 \\
\hline & MO & \multirow{2}{*}{70} & 75.2 & 76.9 & 78.6 & 76.6 & 74.0 & 6.5 & -2.2 & -2.1 & 7.2 & 0.5 \\
\hline & MLO & & 77.0 & 88.4 & 90.1 & 78.6 & 84.8 & 2.4 & -8.1 & -7.2 & 2.6 & -8.0 \\
\hline
\end{tabular}

\subsection{Impulsivity due to single lightweight vehicles}

Fig. 9 to Fig. 12 shows that impulsive characteristics exist for all types of vehicles driven through both TRS types at different running speeds. Based on Fig. 9, most of lightweight vehicles transit on both TRS at lower speed recorded difference values $>2 \mathrm{dBA}$ for $\mathrm{L}_{\mathrm{AImax}}-$ 
$\mathrm{L}_{\mathrm{AFmax}}$. Similar results were also recorded for $\mathrm{L}_{\mathrm{AFmax}}-\mathrm{L}_{\mathrm{Aeq}} \geq 10 \mathrm{dBA}$ as in Fig. 10 . Meanwhile, for $\mathrm{L}_{\mathrm{Aleq}}-\mathrm{L}_{\mathrm{Aeq}}$, most of the vehicles recorded values of $<2 \mathrm{dBA}$ except for sedan driven through MLO at speed of $70 \mathrm{~km} / \mathrm{h}$ which show no significant impulsivity. However, for $\mathrm{L}_{\mathrm{AImax}}-\mathrm{L}_{\mathrm{ASmax}}$, most of the vehicles at different speed driven through both TRS types show impulsivity of $>6 \mathrm{dBA}$. As compared to hatchback and sedan, MPV shows less impulsivity for both TRS types at higher speed. In overall, all single lightweight vehicles transit on TRS show significant impulsive characteristic.

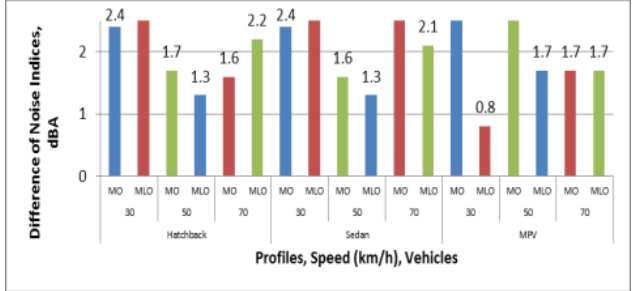

Fig. 9. $\mathrm{L}_{\mathrm{AImax}}-\mathrm{L}_{\mathrm{AFmax}}$

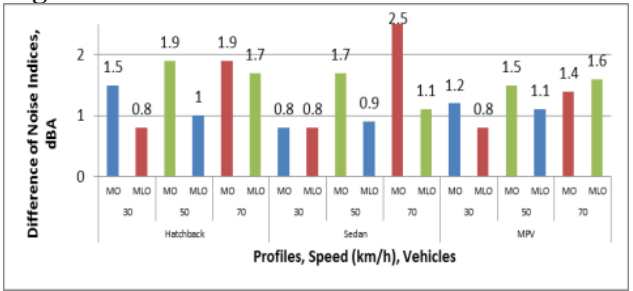

Fig. 11. $\mathrm{L}_{\mathrm{AIeqT}}-\mathrm{L}_{\mathrm{Aeq}}$

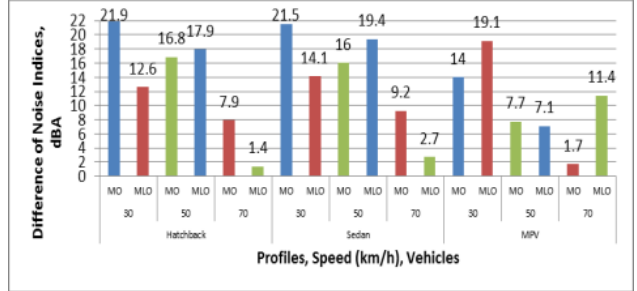

Fig. 10. $\mathrm{L}_{\mathrm{AFmax}}-\mathrm{L}_{\mathrm{Aeq}} \geq 10 \mathrm{dBA}$

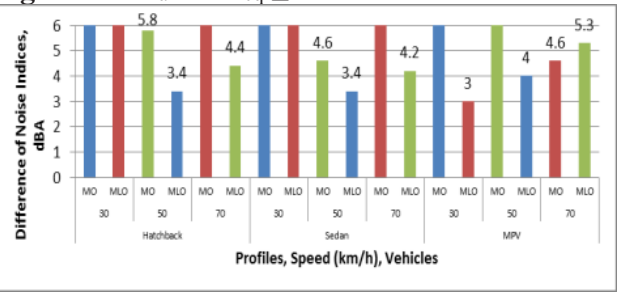

Fig. 12. $\mathrm{L}_{\mathrm{AImax}}-\mathrm{L}_{\mathrm{ASmax}}$

\section{Conclusions}

In conclusion, this study has investigated the impulsivity characteristic of noise due to hatchback, sedan and MPV transit on MO and MLO at speeds of 30, 50 and $70 \mathrm{~km} / \mathrm{h}$. It was found that $\mathrm{MO}$ has significant lower sound level increment with peak level of $2.4 \mathrm{dBA}$ (hatchback) as compared to MLO with peak level of 6.6dBA (MPV). Besides that, hatchback and sedan has lower engine power recorded lower sound level increment as compared to MPV. Overall average increment of $\mathrm{L}_{\text {Aeq }}$ values does not give significant impact when measured with $\mathrm{L}_{\mathrm{Aeq}}$ only. Based on other noise indices such as $\mathrm{L}_{\mathrm{AFmax}}, \mathrm{L}_{\mathrm{AImax}}$, $\mathrm{L}_{\mathrm{AIeqT}}$ and $\mathrm{L}_{\mathrm{ASmax}}$, it can be assumed that the TRS act as a sound damper when vehicles are moving at low speed and power engines. Finally, all single lightweight vehicles transit on TRS show significant impulsive characteristic, which may affect the nearby residents.

The research was funded by GUP Q.J130000.2522.15H28 and FRGS R.J130000.7822.4F887, which was supported by RMC UTM. These supports are highly appreciated.

\section{References}

1. B. N. Persaud, R. A. Retting, C. A. Lyon, Accident Analysis and Prevention 36 (6), 1073 (2004)

2. P. Liu, J. Huang, W. Wang, C. Xu, Accident Analysis and Prevention 43 (6), 1947 (2011) 
3. D. J. Torbic, J. M. Hutton, C. D. Bokenkroger, K. M. Bauer, D. W. Harwood, D. K. Gilmore, C. Lyon, NCHRP Report 641-guidance for the design and application of shoulder and centreline rumble strips (Transportation Research Board, Washington, D. C., 2009)

4. Federal Highway Administration, Shoulder and edge line rumble strips 39 (1), 1 (2011)

5. D. A. Noyce, V. V. Elango, Safety evaluation of centreline rumble strips: a crash and driver behaviour analysis, (Transportation Research Board, Washington, D. C., 2004)

6. T. D. Thompson, M. W. Burris, P. J. Carlson, J. of Trans. Research Board, 1 (2006)

7. D. E. Karkle, M. J. Rys, E. R. Russell, F. Asce, J. of Trans. Eng. 137 (5), 311 (2011)

8. R. Makarla, Master Degree (Kansas State University, 2009)

9. J. S. Higgins, W. Barbel, J. of the Trans. Research Board 27 (1984)

10. Z. Haron, M. H. Othman, L. M. Hee, K. Yahya, M. R. Hainin, N. Darus, M. S. S. Leong. Archives of Acoustics 42(3), 449-457 (2017)

11. Department of Environment, The planning guidelines for environmental noise limits and control (Ministry of Natural Resources and Environment, Malaysia, 2004)

12. International Organization Standardization, Tyres-coast-by methods for measurement of tyre-to-road sound emission: ISO 13325 (Switzerland, 2003)

13. U. Sandberg, J. A. Ejsmont, Tyre/road noise reference book (INFORMEX Ejsmont \& Sandberg Handelbolaj, Kisa, Swesen, 2002)

14. Public Work Department, Manual fasiliti keselamatan jalan raya (Cawangan Kejureteraan Jalan \& Geoteknik, Malaysia, 2014)

15. G. Bahar, T. Erwin, M. MacKay, A. Smiley, S. Tighe, Best practice guidelines for the design and application of transverse rumble strips (Transportation Association of Canada, Canada, 2005)

16. Environmental Protection Agency, Guidance note for noise in relation to scheduled activities: $2^{\text {nd }}$ edition (Environmental Ireland, 2006)

17. International Organization Standardization, Acoustics-guideline for the measurement and assessment of exposure to noise in a working environment: ISO 9612 (Switzerland, 1997)

18. Department of Environment and Resource Management, Noise measurement manual: $3^{\text {rd }}$ edition (Queensland, Australia, 2000)

19. A. Sabato, C. Niezrecki, Rumble strips noise emission effects on urban road traffic, (Noise-Con, 2016) 